\title{
The Study of Footwear Thermal Insulation Using Thermography and the Finite Volume Method
}

\author{
Adam K. Puszkarz ${ }^{1} \cdot$ Adam Usupov $^{2}$ \\ Received: 31 July 2018 / Accepted: 16 March 2019 / Published online: 25 March 2019 \\ (C) The Author(s) 2019
}

\begin{abstract}
The paper concerned the issue of ergonomics and thermal comfort of footwear. The presented work was an attempt to apply selected modeling CAD software and the finite volume method for analysis of heat transfer through footwear between the shoes' user and his surroundings. Based on the actual two selected sport shoes, three-dimensional models have been designed, taking into account their different geometry and raw material composition. The models used simplifications related to the internal construction (in microscale) of the specific parts of the footwear (sole, insole, shank, lining and tongue). The main purpose of the work was to determine the influence of the simplifications used on the accuracy of simulation as a tool to predict thermal insulation of real shoes determined by means of thermal imaging camera. The simulations results were in correlation with the experiment and showed that applied software can be an effective tool in studying the thermophysiological properties of footwear.
\end{abstract}

Keywords CFD · Heat transfer - Shoe designing - Simulation · Thermal comfort . Thermal insulation

\section{Introduction}

Thermal comfort of footwear is one of relevant properties that are taken into account during qualitative evaluation of its functionality and suitability. It results from many various factors related to the activity of the human body. Thermal comfort depends on many factors such as: temperature and humidity inside the footwear, its geometry and thermal properties of the raw materials from which it is made. The thermal properties

Adam K. Puszkarz

adam.puszkarz@p.lodz.pl

1 Department of Material and Commodity Sciences and Textile Metrology, Lodz University of Technology, 116 Zeromskiego Street, 90-924 Lodz, Poland

2 Saxion University of Applied Sciences, Fashion and Textile Technologies, M. H. Tromplaan 28, 7513 AB Enschede, The Netherlands 
of the raw material determine the efficiency of heat and water exchange between the user and his environment, thus affecting the microclimate of the user's foot, which determines the overall comfort of use of the footwear.

Over the decades, increase in production of plastic and synthetic footwear has been observed. The upper parts are mostly made of leather-like materials, while the soles are made from rubber and synthetic materials. Footwear made of synthetic materials does not provide the right comfort during use. Application of artificial leather instead of natural leather (providing a proper thermal balance between the user and its environment), despite enormous progress in the chemical industry, is still unsatisfactory. Usually, the shank is made of genuine leather or synthetic material leather. Soles are usually made from thermoplastic synthetic polymers and from rubber [1]. Currently, the footwear design process is based on advanced computer applications. They enable precise construction of three-dimensional models of shoes as well as conducting virtual researches on footwear functional properties such as mechanics [2-4], thermal comfort [5-10], and sensory comfort [11-17]. Covill et al. [5] developed two-dimensional and three-dimensional thermal models of in-shoe climate were using finite element analysis. The thermal properties of the upper shoe, sole, and air were considered. Dry heat flux from the foot was calculated based on typical blood flow in the arteries on the foot. By means of the thermal models developed, in-shoe temperatures were predicted to cover various locations for various controlled ambient temperatures. Kuklane et al. [6] validated predictions with the model proposed by Lotens (including factors such as blood flow to feet, thermal insulation of footwear and environmental climatic conditions) using actual measurements on subjects exposed to cold environments. The aim of the paper was to check how well the insulation values that were measured on the thermal foot model fit into the prediction model. In other work [7], influence of moisture inside the footwear on the thermal insulation was analyzed. Five types of footwear with various insulation levels were tested. Covill et al. [9] used finite element analysis to describe the heat transfer in footwear. Studies were conducted to determine the temperature distribution in footwear with a variety of environmental temperature and footwear properties considered. Finite element models describing the heat transfer between the foot, sock and shoe were presented with the conductivity, specific heat and density properties of each material presented taken from the literature. On the basis of foot geometry, these models predicted temperatures within footwear with conduction, convection and radiation. One of the most commonly used research methods for evaluation of footwear thermal insulation is the thermal model of the human foot. Endrusick et al. [17] investigated the effects of a simulated environmental exposure on the thermal insulation of an improved version of a military boot designed for use in cold and wet environments. A thermal foot model measured total boot and selected part (toes, heels) thermal resistance values of the standard (non-removable insulation) and the new version of the US Army Intermediate Cold Wet Boot. Kuklane [18] presented work focused on local thermal comfort of feet with special attention to the effects of physical changes on footwear thermal properties. Presented studies have shown that insulation values measured on a thermal foot model correlated with foot skin temperatures measured on subjects. Bergquist and Holmér [19] tested 5 different types of cold-protective footwear with regard to their resistance to dry heat loss (i.e., the insulation) with a new electrically heated foot model. The model was able to 

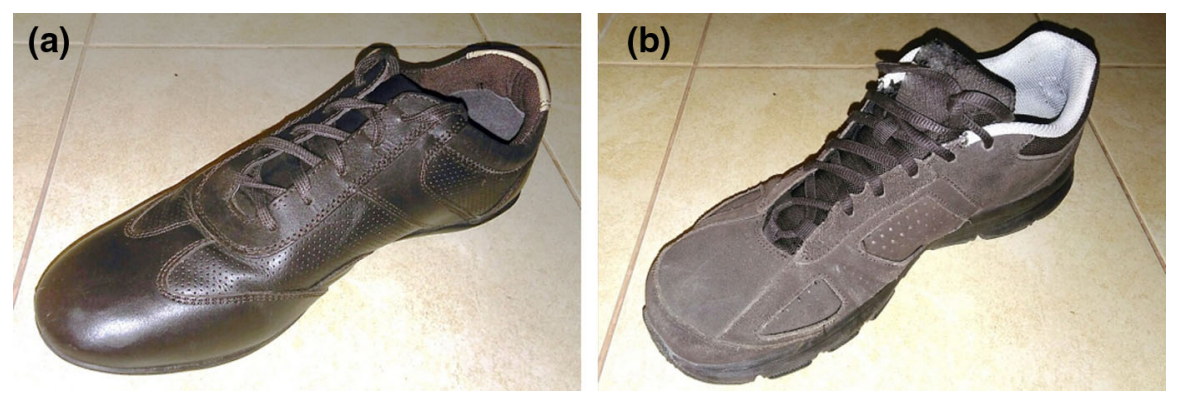

Fig. 1 (a) Shoe A, (b) Shoe B

simulate 'walking' movements in order to provide a more realistic simulation of wear conditions.

The purpose of the work is related to the important problem of thermal comfort [20], and it is a continuation of work on modeling physical phenomena related to the ergonomics of clothing [21-25]. In this work, studies over problems of footwear thermal insulation were presented. The work presents the results of the attempt to use the selected CAD software to simulate thermal insulation of footwear. The main intention of the work was to analyze of heat transfer occurring in footwear during its use and check the usability of the tool in the case of simple models taking into account the shoe geometry and the basic physical parameters of raw materials affecting thermal insulation of analyzed shoes like density, thickness, thermal conductivity coefficient, specific heat. Two selected sport shoes with a different geometry and composition were tested for their thermal insulation. The studies were divided into two parts: experiment and simulation. In experimental part, thermal insulation of actual shoes was measured using a thermal imaging camera. In the simulation part, 3-D models of both shoes were designed and their thermal insulation in selected specific constant ambient conditions was calculated by the finite volume method.

\section{Materials}

The subject of this research was two selected sport shoes (Fig. 1): Shoe A made in China and Shoe $B$ made in Vietnam. The shoes differ in both geometry and raw material composition presented in with a different geometric structure and raw composition (Table 1).

\section{Methods}

\subsection{Experiment}

To assess the thermal insulation, shoes were placed in a room with a constant air temperature: $20^{\circ} \mathrm{C}$. During measurement, a rubber container with water at a temperature of $35^{\circ} \mathrm{C}$ (similar to human foot temperature) was placed inside the shoe. The applica- 
Table 1 Basic characteristics of analyzed shoes

\begin{tabular}{lllll}
\hline Dimension & & Shoe A & & Shoe B \\
\hline Length (mm) & & 261 & 266 \\
Width (mm) & & 121 & 125 \\
Height (mm) & & 94 & 106 \\
\hline Part of shoe & Raw material* & Thickness $(\mathrm{mm})$ & Raw material* & Thickness (mm) \\
\hline Sole & Synthetic rubber & 10.2 & Polyurethane & 25.1 \\
Insole & Natural leather & 2.2 & Polyamide & 2.1 \\
Shank & Natural leather & 3.6 & Natural leather & 4.5 \\
Lining & Natural leather & 2.8 & Polyamide & 3.1 \\
Tongue & Natural leather & 4.3 & Polyamide & 9.1 \\
\hline
\end{tabular}

*Data determined according to the manufacturer

tion of a flexible container ensured equal direct contact with all the inside walls of the footwear, and it provided a conduction heat transfer through shoe walls to the outside. The temperature of the water in the container was controlled by means of a thermometer. After reaching the steady state, the average temperature of outer surface of three selected parts of shoe (sole, shank, tongue) was measured using a thermal imaging camera (FLIR SC5000 model made in USA) and Altair-Thermal Image Analysis Software. Additionally, temperature distribution on the outer surface of the shoe was determined. To determine the temperature distribution, the entire surface of the shoe, the tested shoe (after reaching the steady state), was placed in several orientations relative to the thermal imaging camera. Because different parts of both shoes were made of different raw materials, it would be impossible to assume different values in the settings of the thermal imaging camera during a given measurement. Because the emissivity values did not differ significantly, the averaged emissivity value from all raw materials of tested shoe was applied. The errors of the temperature measurement resulting from thermal imaging camera specifications were $\pm 1{ }^{\circ} \mathrm{C}$. The presented results were the average of three independent experiments. Scheme of the experiment is presented in Fig. 2.

\subsection{Model Design}

Two 3-D models of both shoes (presented in Fig. 3) were developed in SolidWorks 2014 software based on geometry determined on the basis of images of actual shoes.

Both models had the following geometry parameters of the actual shoes: (1) shape of the sole (thickness, profiles, length and width), (2) shape of shank (thickness, profiles), (3) shape of the insole (thickness, profiles length and width), (4) shape of the tongue (thickness, profiles), and (5) shape of the lining (thickness, profiles). The thickness of the individual parts of the shoes has been determined on the basis of their images and application of the ImageJ software (average values are shown in Table 1). The initial phase of the design was to create two-dimensional sketches mapping of complicated 
Fig. 2 Scheme of thermal imaging measurement

$$
\begin{aligned}
& \text { Initial conditions } \\
& T_{\text {air }}=20^{\circ} \mathrm{C} \\
& T_{\text {shoe }}=20^{\circ} \mathrm{C} \\
& T \text { container }=35^{\circ} \mathrm{C}
\end{aligned}
$$

Thermal imaging

camera
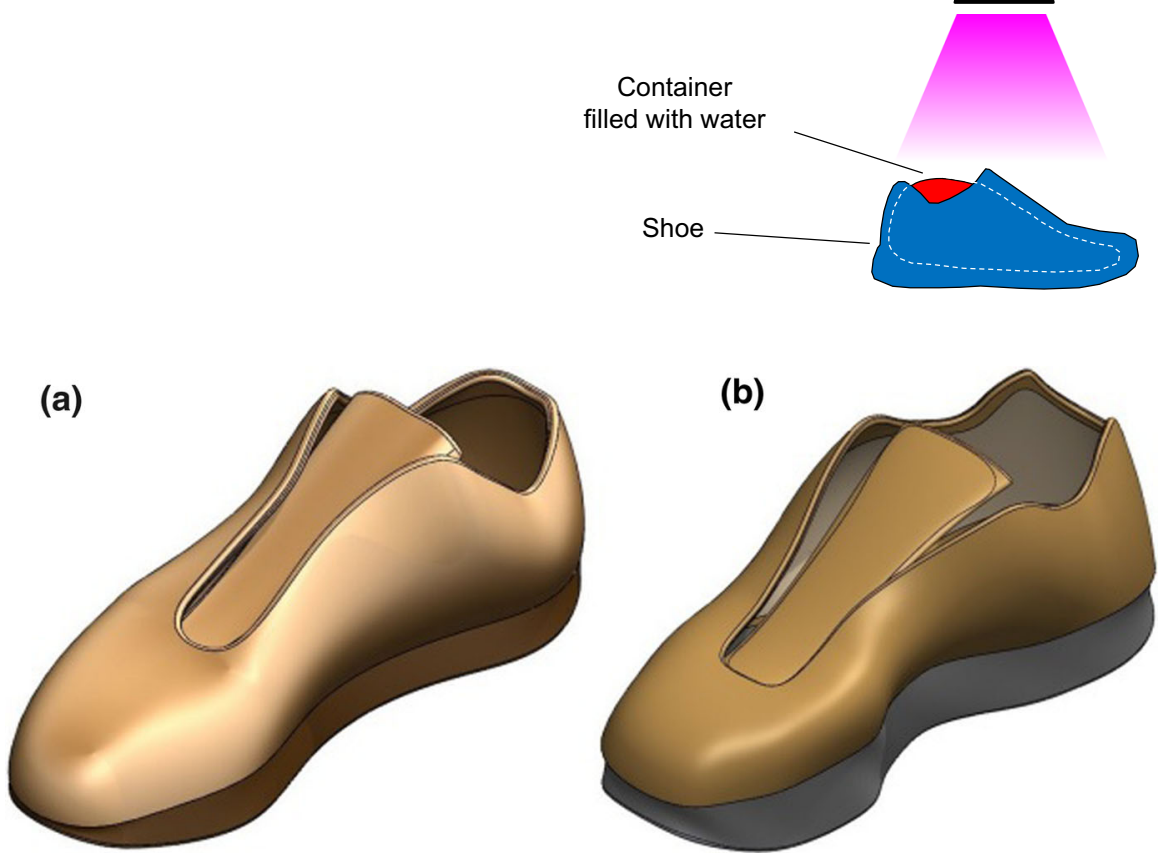

Fig. 3 3-D models of studied shoes: (a) Shoe A, (b) Shoe B

geometry of the mentioned parts of shoes (for example, the shape of the soles in the orthogonal projection) using Non-Uniform Rational B-Spline (NURBS) curves. As a result of the applied operations, two-dimensional sketches were transformed into zero-thickness surface objects. The final stage of the designing was to transform these surfaces into three-dimensional objects. Selected stages of designing footwear models are presented in Fig. 4.

In both models, simplifications regarding the geometry (no holes for laces, no laces, no decorating elements on outer surface of the shank and no treads on the lower surface of the sole) and concerning internal structure (shank, tongue, lining and insole were mapped as a continuous, homogenous objects) of real shoes were applied. In particular, the simplification concerning internal construction obviously had to affect the thermal insulation properties of footwear. All the parts of footwear mapped in the model (sole, insole, lining, shank, tongue) have, in fact, a complex, layered internal structure with inhomogeneous porosity. The air (characterized by a much lower coefficient of thermal 
(a)

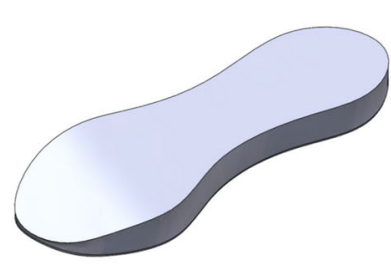

(d)

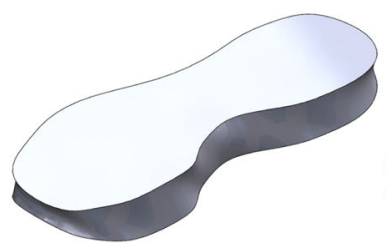

(b)

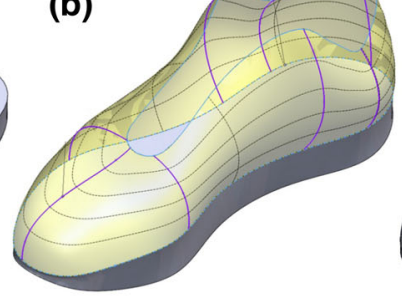

(e)

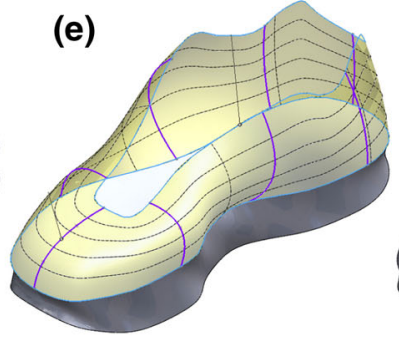

(c)

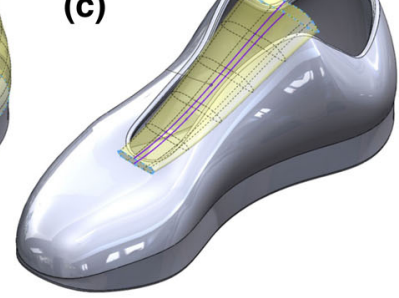

(f)

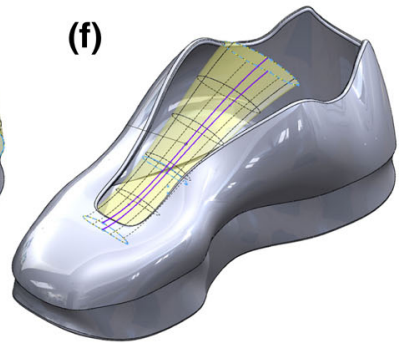

Fig. 4 Stages of designing of 3-D model of studied shoes (a-c) Shoe A, (d-f) Shoe B)

conductivity compared to typical raw materials for the production of footwear) filling space between layers and pores increases the thermal insulation of the footwear.

\subsection{Simulations}

\subsubsection{Physical Basis of Heat Flow Simulation}

The simulations were performed using Solidworks Flow Simulation 2014 software applying computational fluid dynamics (CFD) analysis [26] to enable simulation of heat transfer by the finite volume method.

The software allows predicting simultaneous heat transfer in solid and fluid media with energy exchange between them. Solidworks Flow Simulation solves energy conservation equations and Navier-Stokes formulas describing fluid flow. The software calculates temperature fields created by: (1) heat transfer in solids (conduction), (2) free, forced, and mixed convection, and (3) radiation in both the steady state and transient state [27]. Solidworks Flow Simulation uses the Navier-Stokes equations, which are formulations using momentum and energy conservation and mass laws for fluid flows. Additionally, the software applies fluid state equations defining the nature of the fluid by empirical dependencies of fluid viscosity, thermal conductivity, and density on temperature [27]. The Navier-Stokes equations are supplemented by definitions of thermophysical properties and state equations for the fluids. Solidworks Flow Simulation allows to gas and liquid flow modeling with density, viscosity, thermal conductivity, specific heats, and species diffusivities as functions of pressure, temperature, and species concentrations in fluid mixtures.

Materials used in the production of footwear often have a complicated internal structure. For example, the porous structure makes the thermal properties of footwear 
depend not only on the properties of applied raw material but also on the air inside the pores. Then heat is transported through both (solid body) and fluid (gas), with simultaneous exchange between these environments. Heat transfer in fluids is described by means of the following conservation equation:

$$
\begin{aligned}
\frac{\partial}{\partial t} & {\left[\rho\left(h+\frac{u^{2}}{2}\right)\right]+\frac{\partial}{\partial x_{i}}\left[\rho u_{i}\left(h+\frac{u^{2}}{2}\right)\right] } \\
& =\frac{\partial}{\partial x_{i}}\left[u_{j}\left(\tau_{i j}+\tau_{i j}^{R}\right)+q_{i}\right]+\frac{\partial p}{\partial t}-\tau_{i j}^{R} \frac{\partial u_{i}}{\partial x_{j}}+\rho \varepsilon+S_{i} u_{i}+Q_{H}
\end{aligned}
$$

where $S_{\mathrm{i}}=S_{\mathrm{i}}^{\text {porous }}+S_{\mathrm{i}}^{\text {gravity }}+S_{\mathrm{i}}^{\text {rotation }}$ is the volume-distributed external force per unit volume (in $\left.\mathrm{N} \cdot \mathrm{m}^{-3}\right)$ due to porous media resistance $\left(S_{\mathrm{i}}^{\text {porous }}\right)$, buoyancy $\left(S_{\mathrm{i}}^{\text {gravity }}=\right.$ $\left.-\rho g_{\mathrm{i}}\right)$ and the coordinate system rotation $\left(S_{\mathrm{i}}^{\text {rotation }}\right)$. The subscripts are used to denote summation over the three coordinate directions. The heat flux density is defined by the following equation:

$$
q_{i}=\left(\frac{\mu}{P r}+\frac{\mu_{t}}{\sigma_{c}}\right) \frac{\partial h}{\partial x_{i}} ; \quad i=1,2,3
$$

where

$$
\mu_{t}=\frac{C_{\mu} \rho k^{2}}{\zeta}
$$

The constant $C_{\mu}$ is determined according to [27] as equal to $C_{\mu}=0.09$, whereas $\sigma_{c}=0.9$. The equations describe both laminar and turbulent flows. Moreover, transitions from one case to another and back are possible, $k$ is turbulent kinetic energy, while $\zeta, \mathrm{J} \cdot \mathrm{kg}^{-1} \cdot \mathrm{s}^{-1}$ is turbulence dissipation (rate at which turbulence kinetic energy is converted into thermal internal energy). The parameters $k$ and $\mu_{t}$ are zero for pure laminar flows. The anisotropic heat conductivity in solid media is described by the following equation:

$$
\frac{\partial(\rho e)}{\partial t}=\frac{\partial}{\partial x_{i}}\left(\lambda_{i} \frac{\partial T}{\partial x_{i}}\right)+Q_{H} ;
$$

where $e=c T$. It is assumed that the heat conductivity tensor is diagonal to the considered coordinate system and that the heat transport within analyzed material is direction independent, i.e., we introduce an isotropic medium and can denote $\lambda_{1}=\lambda_{2}=\lambda_{3}=$ $\lambda$. The energy exchange between the fluid and solid media is computed via the heat flux in the direction normal to the solid/fluid interface, taking into account the solid surface temperature and the fluid boundary layer characteristics, if necessary [27].

\subsubsection{Conditions of Simulations}

The aim of simulations was to determine the temperature of the outer surface of three selected parts of the shoes (sole, shank, tongue) using calculation on designed models. 


\begin{tabular}{|c|c|c|c|c|c|}
\hline \multirow[b]{2}{*}{ case } & \multicolumn{5}{|c|}{ initial temperature $\left[{ }^{\circ} \mathrm{C}\right]$} \\
\hline & air & shank & tongue & sole & $\begin{array}{l}\text { inner } \\
\text { surface }\end{array}$ \\
\hline 1 & -10 & -10 & -10 & -10 & 35 \\
\hline 2 & 0 & 0 & 0 & 0 & 35 \\
\hline 3 & 10 & 10 & 10 & 10 & 35 \\
\hline 4 & 20 & 20 & 20 & 20 & 35 \\
\hline
\end{tabular}

Fig. 5 Initial conditions of simulations

Table 2 Physical parameters applied in simulations

\begin{tabular}{lllll}
\hline Physical parameter & Synthetic rubber & Natural leather & Polyurethane & Polyamide \\
\hline Density $\left(\mathrm{kg} \cdot \mathrm{m}^{-3}\right)$ & $910^{\mathrm{a}}$ & $860^{\mathrm{b}}$ & $1200^{\mathrm{c}}$ & $1230^{\mathrm{d}}$ \\
Specific heat $\left(\mathrm{J} \cdot \mathrm{kg}^{-1} \cdot{ }^{\circ} \mathrm{C}^{-1}\right)$ & $1880^{\mathrm{a}}$ & $1500^{\mathrm{b}}$ & $1120^{\mathrm{c}}$ & $2050^{\mathrm{d}}$ \\
Thermal conductivity $\left(\mathrm{W} \cdot \mathrm{m}^{-1} \cdot{ }^{\circ} \mathrm{C}^{-1}\right)$ & $0.13^{\mathrm{a}}$ & $0.14^{\mathrm{b}}$ & $0.035^{\mathrm{c}}$ & $0.220^{\mathrm{d}}$ \\
Emissivity & $0.95^{\mathrm{e}}$ & $0.95^{\mathrm{f}}$ & $0.9^{\mathrm{g}}$ & $0.69^{\mathrm{h}}$ \\
\hline
\end{tabular}

${ }^{\text {a }}$ Data according to [28]

${ }^{b}$ Data according to [29]

c, g Data according to [22]

d,h Data according to [23]

e Data according to [30]

${ }^{\mathrm{f}}$ Data according to [31]

The initial conditions of simulation (presented in Fig. 5) imitated real conditions during use of the footwear in four selected ambient temperature $-10{ }^{\circ} \mathrm{C}, 0{ }^{\circ} \mathrm{C}, 10^{\circ} \mathrm{C}$, and $20^{\circ} \mathrm{C}$, pressure $1013.25 \mathrm{hPa}$, while assumed temperature inside of the shoes was equal to human foot temperature: $35^{\circ} \mathrm{C}$.

The raw materials with physical properties presented in Table 2 , have been assigned to the tested models.

During calculations, the analyzed shoe model was placed in the center of computational domain (presented in Fig. 6) divided into cells of three types (fluid cells, solid cells, and partial cells).

Fluid cells were filled with air, solid cells filled with shoe, while the partial cells contained both air and shoe. The number of cells (presented in Table 3) was dependent on the number and size of the elements making up the model of particular shoe. 


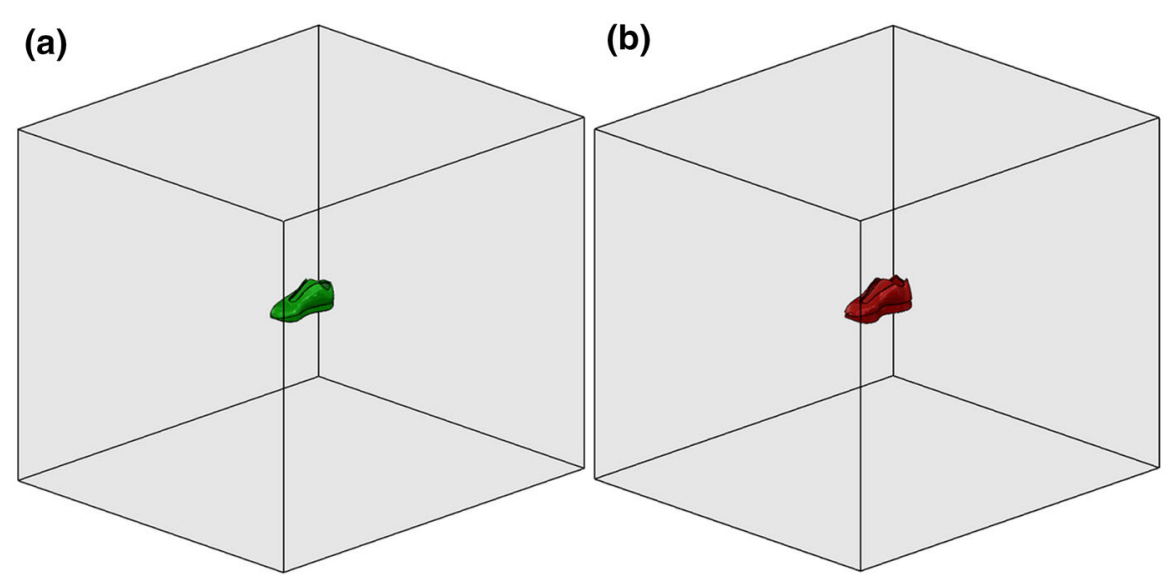

Fig. 6 Shoe models in computational domains [(a)—Shoe A, (b)—Shoe B]

Table 3 Number of cells in both shoe models

\begin{tabular}{lllll}
\hline Model & \multicolumn{4}{l}{ Number of cells } \\
\cline { 2 - 5 } & Partial & Fluid & Solid & All \\
\hline Shoe $A$ & 28482 & 12578 & 10398 & 51458 \\
Shoe $B$ & 36140 & 14414 & 12009 & 62563 \\
\hline
\end{tabular}

\section{(a)}

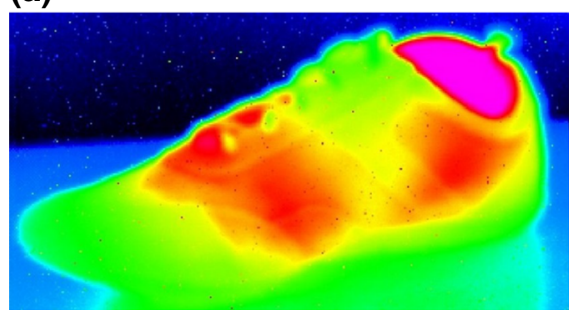

(b)

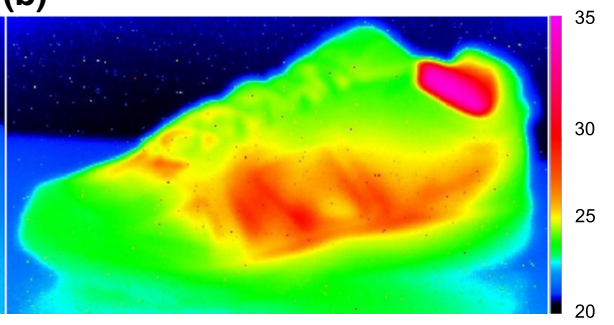

Fig. 7 Temperature distributions on outer surfaces of real shoes for ambient temperature: $20^{\circ} \mathrm{C}$ obtained by thermal imaging camera (a) Shoe A, (b) Shoe B

\subsection{Results and Comments}

The images obtained by means of thermal imaging camera (presented in Fig. 7) show temperature distribution on outer surface of both shoes in ambient temperature: $20^{\circ} \mathrm{C}$ after a period of about $15 \mathrm{~min}$ when the steady state was reached.

The area marked in pink color indicates a temperature of $35^{\circ} \mathrm{C}$ of container filled with a water placed inside the shoes. The obtained images showed that in case of both shoes the highest temperature (red color) was observed in the middle part of the shank and the lower part of the tongue, where temperatures ranged from $33{ }^{\circ} \mathrm{C}$ to $28{ }^{\circ} \mathrm{C}$. 

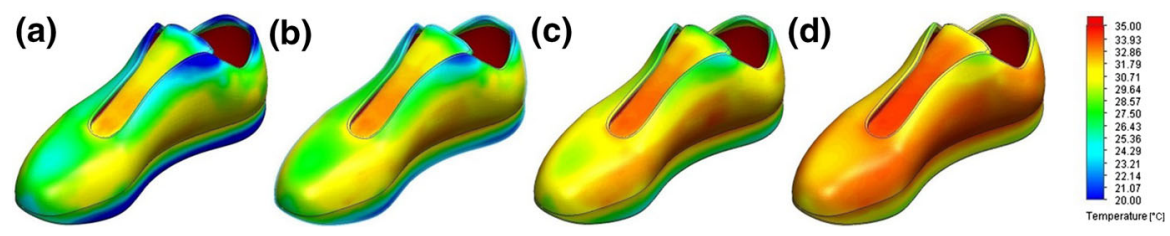

Fig. 8 Temperature distributions on outer surfaces of Shoe A model for four different ambient temperatures: (a) $-10{ }^{\circ} \mathrm{C}$, (b) $0{ }^{\circ} \mathrm{C}$, (c) $10{ }^{\circ} \mathrm{C}$, (d) $20{ }^{\circ} \mathrm{C}$ obtained by simulations
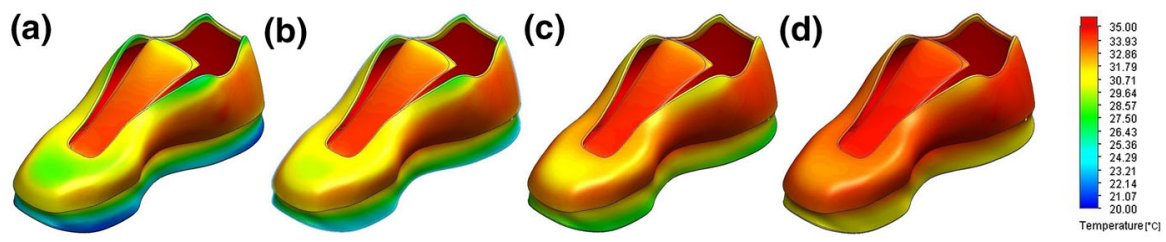

Fig. 9 Temperature distributions on outer surfaces of Shoe $B$ model for four different ambient temperatures: (a) $-10{ }^{\circ} \mathrm{C}$, (b) $0{ }^{\circ} \mathrm{C}$, (c) $10{ }^{\circ} \mathrm{C}$, (d) $20{ }^{\circ} \mathrm{C}$ obtained by simulations

Visibly cooler parts were: the sole, toe cap, quarter, collar, and upper part of tongue. In Figs. 8 and 9, temperature distributions on outer surfaces of both shoe models, calculated for four ambient temperatures: $-10^{\circ} \mathrm{C}, 0{ }^{\circ} \mathrm{C}, 10^{\circ} \mathrm{C}, 20^{\circ} \mathrm{C}$, were presented.

The simulation and experiment results obtained for ambient normal conditions show the heterogeneity of the temperature distribution on all three analyzed parts of the footwear. In addition, areas with the same temperature on the corresponding parts of the shoe differ in shape and temperature value. As can be seen in the experimental and simulated temperature distributions, the area with the highest temperature was the middle part of the shank, while the coolest parts were: the sole, toe cap, quarter, collar and upper part of tongue. Differences in shape of the corresponding temperature fields between experiment and simulation resulted probably from the heterogeneous internal structure of parts of real shoes (sole, insole, shank, tongue), while the both shoe models establish their uniform internal structure. In Table 4, temperature values (minimum, average, maximum) obtained using simulated and experimental distributions on analyzed parts of both shoes determined in normal ambient conditions were presented. Experimental average temperature $T_{\mathrm{av}}$ of the given part of shoe (sole, shank, tongue) was calculated as a weighted average temperature of individual pixels of thermogram included in the analyzed part. Simulated average temperature was calculated on the basis of simulated distributions in the same way like experimental. The extreme values, on the other hand, were points with highest and lowest temperatures for the analyzed part of the shoe, which were determined on the basis of the experimental and simulated distributions. In addition, the percentage differences between simulated and experimental temperature values are shown in Table 4.

In Fig. 10, average temperature on outer surface of three selected parts of tested shoes in four ambient temperatures computed by simulations and determined in the experiment was presented. 
Table 4 Temperature values (minimum, average, maximum) of simulated and experimental distributions on analyzed parts of both shoes obtained in normal ambient conditions

\begin{tabular}{|c|c|c|c|c|c|c|c|c|c|}
\hline \multirow{2}{*}{$\begin{array}{l}\text { Part of } \\
\text { shoe }\end{array}$} & \multicolumn{3}{|c|}{ Simulation } & \multicolumn{3}{|c|}{ Experiment } & \multicolumn{3}{|c|}{ Percentage differences } \\
\hline & $\begin{array}{l}T_{\min } \\
\left({ }^{\circ} \mathrm{C}\right)\end{array}$ & $\begin{array}{l}T_{\mathrm{av}} \\
\left({ }^{\circ} \mathrm{C}\right)\end{array}$ & $\begin{array}{l}T_{\max } \\
\left({ }^{\circ} \mathrm{C}\right)\end{array}$ & $\begin{array}{l}T_{\min } \\
\left({ }^{\circ} \mathrm{C}\right)\end{array}$ & $\begin{array}{l}T_{\mathrm{av}} \\
\left({ }^{\circ} \mathrm{C}\right)\end{array}$ & $\begin{array}{l}T_{\max } \\
\left({ }^{\circ} \mathrm{C}\right)\end{array}$ & $\begin{array}{l}\Delta T_{\min } \\
(\%)\end{array}$ & $\begin{array}{l}\Delta T_{\mathrm{av}} \\
(\%)\end{array}$ & $\begin{array}{l}\Delta T_{\max } \\
(\%)\end{array}$ \\
\hline \multicolumn{10}{|l|}{ Shoe A } \\
\hline Sole & 27.6 & 28.5 & 31.9 & 24.6 & 27.5 & 29.1 & 12.2 & 3.6 & 9.6 \\
\hline Shank & 29.7 & 31.5 & 32.4 & 25.5 & 30.1 & 31.4 & 16.5 & 4.7 & 3.2 \\
\hline Tongue & 30.6 & 32.1 & 33.9 & 25.1 & 31.2 & 32.7 & 21.9 & 2.9 & 3.7 \\
\hline \multicolumn{10}{|l|}{ Shoe B } \\
\hline Sole & 29.1 & 29.7 & 31.8 & 24.8 & 28.7 & 30.6 & 17.3 & 3.5 & 3.9 \\
\hline Shank & 30.9 & 31.4 & 33.8 & 25 & 30.4 & 32.5 & 23.6 & 3.3 & 4.0 \\
\hline Tongue & 31.8 & 32.3 & 34.1 & 26.2 & 31.6 & 32.2 & 21.4 & 2.2 & 5.9 \\
\hline
\end{tabular}
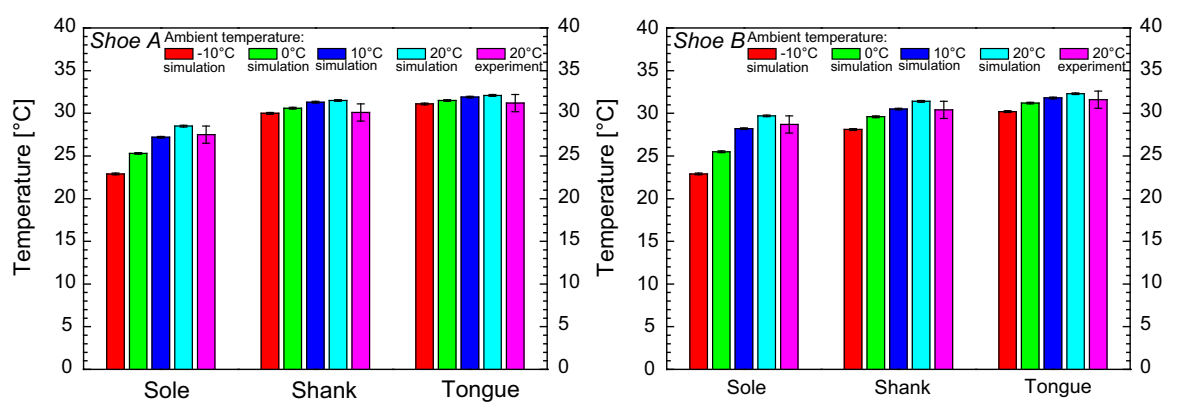

Fig. 10 Average temperature on outer surface of three selected parts of tested shoes in four ambient temperatures determined in the experiment and calculated by simulations (error bars indicate measurement and calculation uncertainties)

Simulation results revealed that the average temperatures of three selected parts of shoes increased in higher ambient temperatures. For both tested shoes, the largest temperature differences determined for different ambient conditions occurred for soles, which probably resulted from their much bigger thickness in comparison with thickness of shanks and tongues. However, these differences were clearly bigger for sole of Shoe B, which could be the result of their bigger thickness and lower heat conduction coefficient of raw material (polyurethane), and the sole of Shoe A was made of synthetic rubber. In addition, for shank and tongue in Shoe $B$ temperature differences were larger than for Shoe A. Although these parts in both shoes were made of the same raw materials, they clearly differed in thickness.

Outcomes of thermal imaging conducted for the ambient temperature $20{ }^{\circ} \mathrm{C}$ confirmed that in the two analyzed shoes a sole was the most thermo-insulating part, while a tongue was the least one. The results of the experiment showed that average temperature of three analyzed parts was always lower than the calculated one. The percentage differences between simulated and experimental values of average temperature of the given part of footwear (both obtained in normal climate) were as follows: $\Delta T_{\text {sole }}=$ 
$3.6 \%, \Delta T_{\text {shank }}=4.7 \%, \Delta T_{\text {tongue }}=2.9 \%$ for Shoe $A$ and $\Delta T_{\text {sole }}=3.5 \%, \Delta T_{\text {shank }}$ $=3.3 \%, \Delta T_{\text {tongue }}=2.2 \%$ for Shoe $B$. However, the differences in average values are not sufficient to fully assess the usefulness of the designed models. The comparison of extreme temperature values (Table 4) showed that the differences between the results of the experiment and modeling are greater. The biggest differences between the results of the simulation and the experiment were observed in the case of minimum temperatures (16.5\%-21.9\% in the case of Shoe $A$ and $17.3 \%-23.6 \%$ in the case of Shoe B). Significantly smaller differences were observed in the case of maximum temperatures $(3.7 \%-9.6 \%$ in the case of shoe $A$ and $3.9 \%-5.9 \%$ in the case of shoe B). Small differences in the case of simulation and experimental values of average temperatures and much clearer differences in the case of extreme temperatures can be a decisive influence of the complex internal structure of the analyzed footwear which should be taken into account when analyzing the evaluation of its thermal insulation. For both analyzed shoes, the greatest differences in extreme temperatures were found in the shank and the tongue, i.e., parts with a much higher porosity than the sole. The main reason for this could be the fact that both parts are characterized by higher porosity, more complicated geometry, and a more heterogeneous internal structure than the sole.

Despite applied simplifications, simulation results obtained at normal climate correlated with the experiment and showed influence of geometry and raw material composition of the three analyzed parts of both shoes on their thermal insulation.

\section{Conclusions}

In the work, the issues related to the thermal comfort of footwear were studied. An attempt to use the selected CAD software to design three-dimensional models of two selected actual sports shoes (differing in geometry and raw material composition) in order to determine their thermal insulation properties using the finite volume method was presented. Designed models mapped both the geometry and the raw material composition of the real footwear. In first applied approach for both shoe models, significant simplifications in mapping of internal structure of analyzed parts (shank, tongue, lining and insole were modeled as a continuous, homogenous, non-porous objects) were applied. The main goal of this approach was to attempt to assess the impact of the simplifications used on the accuracy of simulation as a tool to predict thermal insulation of real shoes determined by means of thermal imaging camera. Obtained simulation results led to the following conclusions:

1. The simulations outcomes were in correlation with the experiment; however, in the case of both shoes, the thermal insulation calculated by means of simulation was slightly lower than that determined in the experiment.

2. Not taking into account in both models the complex internal structure of real shoes, in particular heterogeneity, porosity and thus the free spaces filled by air decreased simulated thermal insulation.

3. Obtained differences between experimental and the simulation temperature distributions for footwear models indicate the need to correct these models, probably in 
the direction of increasing its similarity to the structure parameters of actual shoes as:
a. heterogeneous internal structure
b. heterogeneous porosity

4. Obtained differences between experimental and the simulation results may also be caused by the method of conducting experimental research (application of a common average value of emissivity for all raw materials forming shoes)

5. Despite the above-mentioned simplifications of applied software and developed geometrical footwear models allowed to predict the average temperatures of analyzed parts of real shoes with the error on the level of $2.9 \%-4.7 \%$ (Shoe A) and $2.2 \%-3.5 \%$ (Shoe B) in relation to the verification experiment.

6. The presented models could be useful in predicting the thermal comfort of the designed and manufactured footwear containing raw materials like natural leather, synthetic rubber, polyurethane and polyamide.

Acknowledgements Open Access This article is distributed under the terms of the Creative Commons Attribution 4.0 International License (http://creativecommons.org/licenses/by/4.0/), which permits unrestricted use, distribution, and reproduction in any medium, provided you give appropriate credit to the original author(s) and the source, provide a link to the Creative Commons license, and indicate if changes were made. https://www.springer.com/gp/open-access/springer-open-choice/springer-compact/ springer-open-choice-for-polish-institutions/11027898. These studies were financed from funds assigned from 14-148-1-2118 statutory activity by the Lodz University of Technology, Department of Material and Commodity Sciences and Textile Metrology, Poland and realized as part of the Erasmus+2014-2020 Textile Project.

Open Access This article is distributed under the terms of the Creative Commons Attribution 4.0 International License (http://creativecommons.org/licenses/by/4.0/), which permits unrestricted use, distribution, and reproduction in any medium, provided you give appropriate credit to the original author(s) and the source, provide a link to the Creative Commons license, and indicate if changes were made.

\section{References}

1. Z. Olejniczak, B. Woźniak, Hygienic shoe properties. Technologia i Jakość Wyrobów 59, 23-27 (2014)

2. S. Koike, S. Okina, Procedia Eng. 34, 272-277 (2012)

3. T. Nishiwaki, M. Nonogawa, Procedia Eng. 112, 314-319 (2015)

4. I. Hannah, A. Harland, D. Price, T. Lucas, Procedia Eng. 34, 278-283 (2012)

5. D. Covill, Z.W. Guan, M. Bailey, H. Raval, Proceedings of the institution of mechanical engineers. Part H J. Eng. Med. 268-281, (2010)

6. K. Kuklane, I. Holmér, G. Havenith, J. Physiol. Anthropol. Appl. Hum. Sci. 19, 29-34 (2000)

7. K. Kuklane, I. Holmér, G. Giesbrecht, Appl. Hum. Sci. J. Physiol. Anthropol. 18, 161-168 (1999)

8. P. Hofer, M. Hasler, G. Fauland, T. Bechtold, W. Nachbauer, Procedia Eng. 13, 44-50 (2011)

9. D. Covill, Z. Guan, M. Bailey, D Pope, Finite element analysis of the heat transfer in footwear (P186). In The Engineering of Sport 7. Springer, Paris (2009)

10. E. Irzmańska, M. Okrasa, Int. J. Ind. Ergon. 67, 27-31 (2018)

11. C.-S. Wang, Comput. Ind. 61, 532-540 (2010)

12. K. Tao, D. Wang, X. Wang, A. Liu, C.J. Nester, D. Howard, J. Bionic Eng. 6, 387-397 (2009)

13. J.A. Bernabéu, M. Germania, M. Mandolini, M. Mengonia, C. Nester, S. Preec, R. Raffaeli, Comput. Aided Des. 45, 977-990 (2013)

14. T.-X. Qiu, E.-C. Teo, Y.-B. Yan, W. Lei, Med. Eng. Phys. 33, 1228-1233 (2011)

15. P. Franciosa, S. Gerbino, A. Lanzotti, L. Silvestri, Med. Eng. Phys. 35, 36-46 (2013)

16. A. Luximon, Y. Luximon, Comput. Ind. 60, 621-628 (2009) 
17. T.L. Endrusick, I.D. Cole, P.M. Matonich, Effects of simulated sustained operations on the thermal insulation of military footwear. Elsevier Ergon. Book Ser. 3, 389-393 (2005)

18. K. Kuklane, Int. J. Occup. Saf. Ergon. JOSE 10, 79-86 (2004)

19. K. Bergquist, I. Holmér, Appl. Ergon. 28, 383-388 (1997)

20. A.S. Ribeiro, J. Alves e Sousa, M.G. Cox et al., Int. J. Thermophys. 36, 2124 (2015). https://doi.org/ 10.1007/s10765-015-1888-1

21. A.K. Puszkarz, R. Korycki, I. Krucinska, Autex Res. J. 16, 128-137 (2015). https://doi.org/10.1515/ aut-2015-0042

22. A.K. Puszkarz, I. Krucinska, Fibres Text. East. Eur. 24 6, 129-137 (2016)

23. A.K. Puszkarz, I. Krucinska, Text. Res. J. 87, 643-656 (2016). https://doi.org/10.1177/ 0040517516635999

24. A.K. Puszkarz, I. Krucinska, Autex Res. J. 18, 364-376 (2018). https://doi.org/10.1515/aut-2018-0007

25. A.K. Puszkarz, I. Krucinska, Int. J. Multiscale Comput. Eng. 16, 509-526 (2018). https://doi.org/10. 1615/IntJMultCompEng.2018022099

26. J. Yang, Q.Q. Liu, R.H. Ding, Int. J. Thermophys. 38, 12 (2017). https://doi.org/10.1007/s10765-0162151-0

27. SolidWorks Flow Simulation - Technical Reference 2014

28. www.matbase.com

29. www.engineeringtoolbox.com

30. https://www.thermoworks.com/emissivity_table

31. https://www.optotherm.com/emiss-table.htm

Publisher's Note Springer Nature remains neutral with regard to jurisdictional claims in published maps and institutional affiliations. 